\title{
Cardiovascular Diseases and Radiations
}

\author{
Abdulmagid Sherif, Mohamed Benhammuda, Serag Fares, Terry L. Oroszi \\ Department of Pharmacology and Toxicology, Boonshoft School of Medicine, Wright State University, Dayton, OH, USA \\ Email: sherif.3@wright.edu
}

How to cite this paper: Sherif, A., Benhammuda, M., Fares, S. and Oroszi, T.L. (2017) Cardiovascular Diseases and Radiations. Journal of Biosciences and Medicines, 5, 72-77.

https://doi.org/10.4236/jbm.2017.52007

Received: January 1, 2017

Accepted: February 21, 2017

Published: February 24, 2017

Copyright (c) 2017 by authors and Scientific Research Publishing Inc. This work is licensed under the Creative Commons Attribution International License (CC BY 4.0).

http://creativecommons.org/licenses/by/4.0/

\begin{abstract}
Human beings have continually been exposed to radiation from sources that are terrestrial. There are different sources of radiation for instance ubiquitous background and medical exams that require X-rays. In America for example, the rate of radiation intake per individual increased from 1.6 to $6.2 \mathrm{mSv}$. The increase has been associated with increased imaging procedures in healthcare facilities. The continued exposure of people to radiant's increases their rates of developing cardiovascular related diseases. A person who is exposed to low amounts of radiation over a long duration may in the long run develop heart diseases. The result has been obtained from an experiment with the Japanese survivors of the atomic bomb. This research paper focuses on the different sources of radiations and the risk of contracting cardiovascular diseases. The paper also explains the possible relationship between radiations and cardiovascular diseases.
\end{abstract}

\section{Keywords}

Radiation, Exposure, Human Health, Cardiovascular Diseases, Sources of Radiations, Radiation Accidents, Radiological Terrorism, Cancer Patients, International Atomic Energy Agency (IAEA)

\section{Introduction}

Exposure to radiation may affect different parts of the body based on the different sources of the radiation. There are other factors that determine the rate at which the health of the body is affected. Some of the factors include the amount of the dose to which a person is exposed to the radiation's potential to harm the human body tissues and the organs which are affected by the radiations. The most important factor that determines the effect of the radiation is the amount of the dose to which an individual is exposed by Vrijheid et al. [1]. The amount of radiation is actually the energy amount that is deposited in the body. When there is more energy deposited on the body tissues, there is a possibility that 
most of the cells will be damaged. The amount of radiation that gets into the human body is referred to as the radiation dose. Radiation has health effects on many organs in the body. Some of the major body parts affected by the radiation include the hair, brain, thyroid, bloodstream, gastrointestinal tract, heart and the reproductive tract [2].

The effects of radiations to the heart lead to serious damages in the cardiovascular system. When radiation affects the bloodstream, there is no doubt that cardiovascular diseases will be experienced. Exposure to radiations leads to damage of the small blood vessels in the heart which leads to their being damaged thus cardiovascular disorders [2]. Once the small blood vessels are damaged, some disorders such as heart failure may result which will then lead to deaths of the people affected. On the other hand, radiation may lead to a reduction of lymphocyte cells in the bloodstream which will then lead to a reduction of the blood flowing into the heart [3]. A strained heart will develop disorders that will eventually cause health effects in the body. Effects on the bloodstream may also lead to development of other blood disorders such as leukemia and lymphoma. Persistence of such disorders leads to thriving of heart diseases which may in the long term lead to deaths of the affected persons.

\section{Sources of Radiation}

Atomic bombs are a major source of radiation as they are composed of neutrons and gamma rays. They form part of the nuclear weapons thus contain high amounts of radiations. The atomic bomb that exploded in Hiroshima and Nagasaki left many people having been exposed to radiations. Most of the survivors showed high doses of radiation intakes into their bodies. The effects of the radiations have continued being passed on from one generation to other since the bombing took place. After the bombing, the rates of people dying from heart diseases increased by $17 \%$. Research explained that most of the bomb survivors who suffered moderate intake of the radiation doses increased the rate at which they died as a result of cardiovascular disorders [4]. Some of the common diseases that have been caused by the radiation exposure include stroke and heart failures. Some bomb survivors have died cancer caused by the radiations. Yet, those who died heart diseases are more.

Other sources of radiations include radiation accidents which are associated with nuclear power plants after production of large amounts of radiations which can affect the lives of people working in them in case of an accident takes place. For instance, there was an accident in the year 1986 at Chernobyl nuclear plant was the most severe accident which led to deaths of many people. Most of the workers were severely harmed [5]. These accidents also expose people to large doses of gamma and beta emissions that contribute to their development of cardiovascular diseases in the long run.

Radiological terrorism is also a source of radiations which threaten the heath of individuals. Vital organs in the body are destroyed and major effects are presented with the heart. According to International Atomic Energy Agency (IAEA) 
there are more than 175 cases of nuclear attacks that have resulted into exposure of radiations to many people [6]. Nuclear plants have waste sites containing radiations that threaten human health. Some terrorists have used the waste sites to expose many people to radiations. Other sources of radiations include energy plants which use different types of fuels. The fuels may contain high amounts of radioactive materials and are a health hazard when people are exposed to them. Continued exposure to the radioactive materials leads to health complications such as the cardiovascular diseases. The chart below (Figure 1) represents percent contribution of various sources of radiation exposures.

\section{Relationship between Cancer and Cardiovascular Diseases}

Most of the cancers are treated through therapies which require the patient to be exposed to different types of radiations. The radiations are applied with the aim of killing the cancerous cells in the human body. However, after a long exposure to the radiations, there are other complications that may develop. A patient may heal from cancer but develop other diseases that are cardiovascular in nature. Cardiovascular diseases are evident later in life after one stopping the radiotherapies for cancer treatment. There is therefore a connection between cancer and cardiovascular disorders. However, the relationship exists due to the fact that there is application of radiations in the treatment of cancer which later lead to cardiovascular diseases [2]. In most cases, cancer patients later die as a result of coronary artery disorders after they have recovered from cancer. Some of the other diseases associated with radiotherapies include congestive failure of the heart and valvular disease of the heart. There are also other cases when patients suffer from pericardial diseases which lead to sudden deaths.

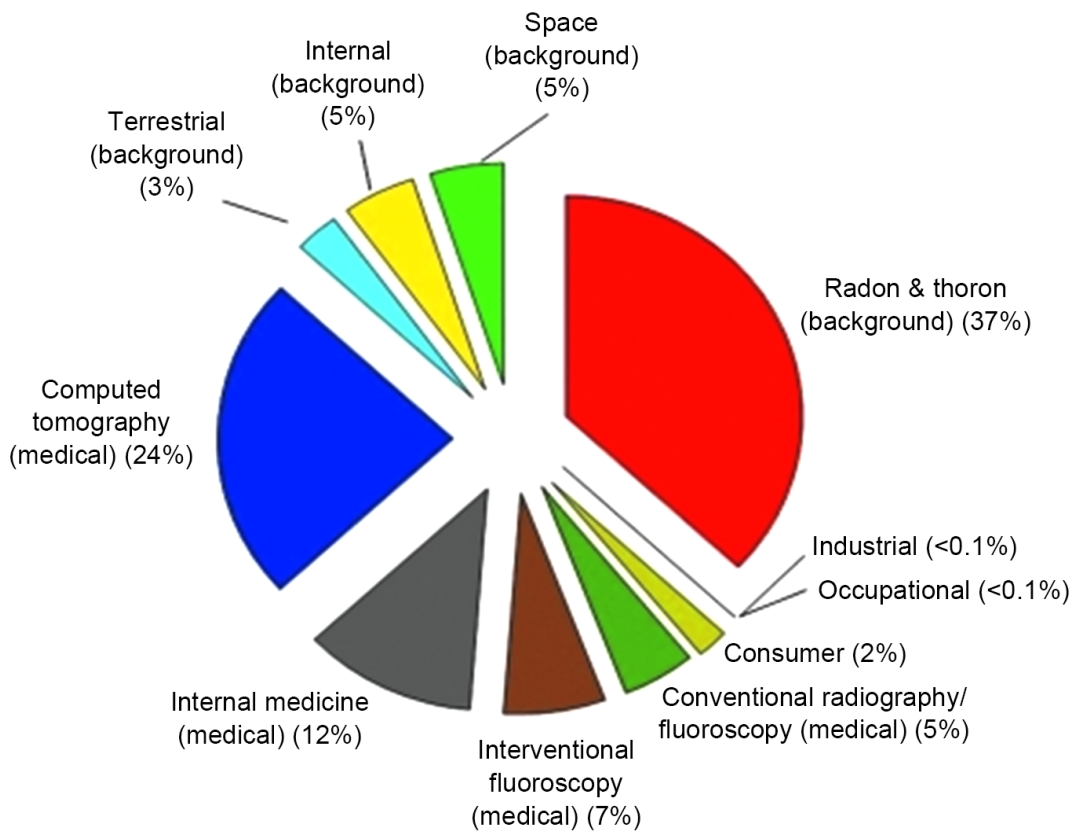

Figure 1. Contribution of various sources of radiation exposures. 


\section{How Radiations Cause Cardiovascular Diseases}

There is no exact way that can be used to explain how the cardiovascular diseases are caused by radiations. However, there are claims that there are some effects such as endothelial damage cell infiltration that is inflammatory and activation of the lysosomes. However, the best way to explain how cardiovascular diseases are caused by radiation is through the dysfunction of the Endothelium.

There are also other factors that increase the risk of radiations causing heart diseases. For instance, smoking and other risk factors such as hyperlipidemia seem to be accelerating the rate of cardiovascular disorders in people who have previously been exposed to radiations [7]. Radiations cause fibrotic changes on the coronary artery. However, radiations on their own do not result into arthrosclerosis. Research has found that another risk factor that leads to development of the condition include cholesterol. People who have high levels of cholesterol are prone to contracting cardiovascular disorders after exposure to radiations. On the other hand, people with less cholesterol in their bodies may take long before contracting heart diseases after exposure to radiations [8]. The presence of high cholesterol levels can cause build up on artery walls. The build-up causes stiffening of the arteries and this condition is known as atherosclerosis. The arteries become narrow and this reduces blood flow to the heart muscle. The reduced blood flow can result in to a heart attack in case a blood vessel becomes completely blocked [9]. Below (Figure 2) is a summary of the pathology of radiation induced heart diseases.

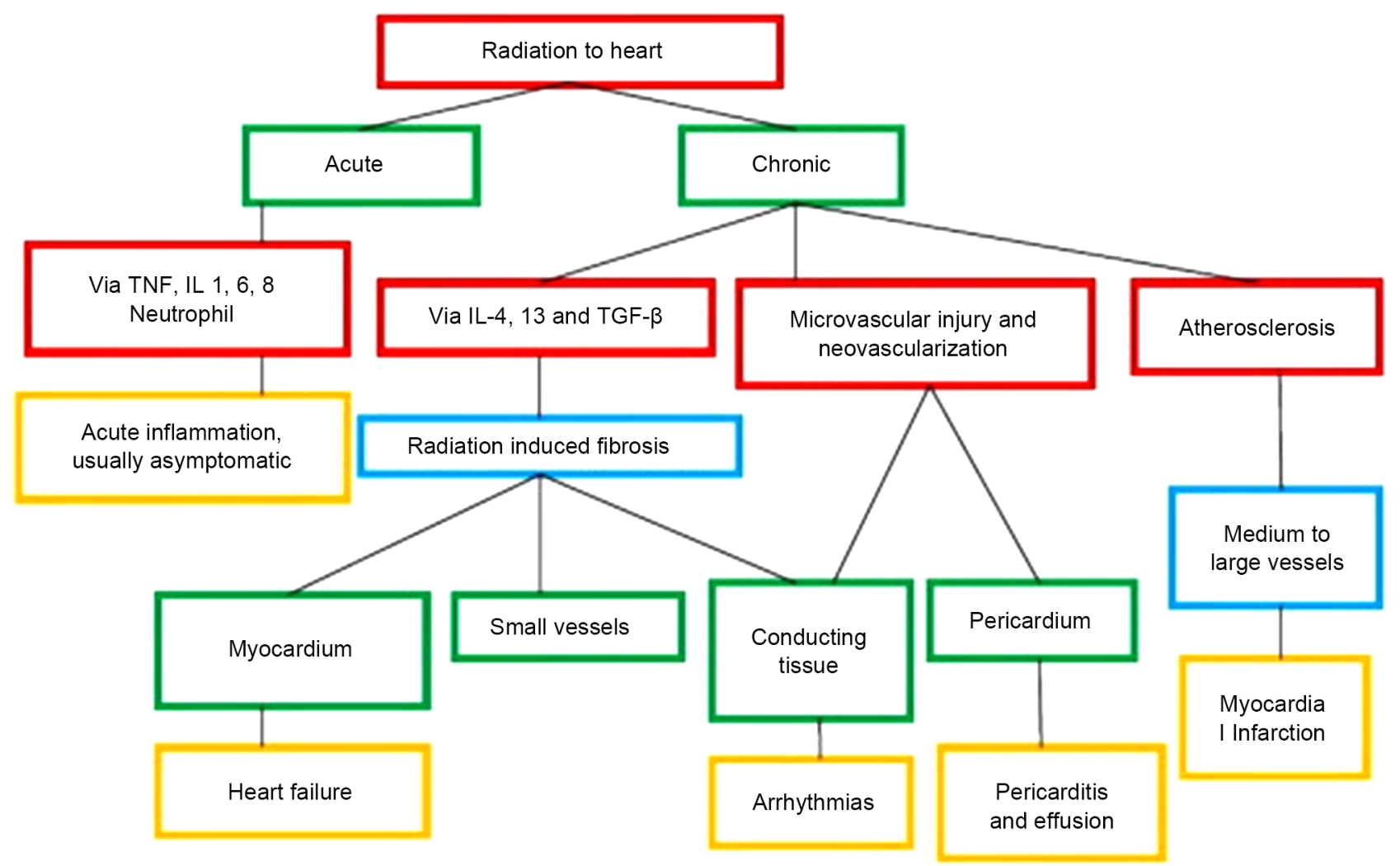

Figure 2. A summary of the pathology of radiation induced heart diseases. 
Researchers have also postulated that radiations facilitate the occurrence of changes in the body that are short lived where an individual suffers from oxidative stress present in the arteries. As a result, high fat content diet has resulted into many people being highly affected by radiations. Endothelial dysfunction was also facilitated by the body producing oxygen species that are reactive. For instance, people who were exposed to high amounts of radiations showed high levels of super oxides as well as peroxides in their micro vessels [10]. When the nuclear factor, kappa is activated in the human body as a result of radiation, inflammatory damage is present in the vascular vessels. There are also other factors stimulating endothelial proliferation that is induced by radiation. Some other risks that were associated with radiations included endothelial proliferation, fibrosis, fibroblast proliferation and collagen deposition. These risk factors lead to advanced lesions associated with atherosclerosis. There are some chemicals that are produced by the endothelial cells after exposure to radiations include thrombomodulin. The chemical and others result into cardiovascular disorders and may in the long term lead to death.

\section{Conclusion}

Exposure to radiation is a key factor in the development of cardiovascular diseases. The effects of radiation or development of the cardiovascular disease may take time to develop after the initial exposure but with continued exposure, the disorders become evident. The level of radiation exposure also matters since the cardiovascular conditions are directly related to the levels of exposure; therefore the higher the levels of radiation the more serious the conditions will be [11]. High levels of exposure to radiation may even run through the generations of the exposed individuals or people, for instance the case of bombing in Japan. Governments and health organizations should endorse the reduction in the radiation exposure levels. This includes limitations in the use of X-rays and gamma radiators in the medical field and shifting to less dangerous methods of scanning and tests. Nuclear plants should also be automated and controlled and manned by robots and remote computers to reduce the possibility of death in case of the occurrence of an accident. Protective clothing should also be a compulsory option for those working in areas with high radiations to keep their health a priority. The high relationship between cancer and cardiovascular diseases is the treatment therapies that are radiation based. The high radiations applied in cancer therapies facilitate the development of cardiovascular disorders. This means that cancer patients may recover from cancer but they often develop cardiovascular diseases later on in life.

\section{References}

[1] Vrijheid, M., Cardis, E., Ashmore, P., Auvinen, A., Bae, J.M., Engels, H. and Kurtinaitis, J. (2007) Mortality from Diseases Other than Cancer Following Low Doses of Ionizing Radiation: Results from the 15-Country Study of Nuclear Industry Workers. International Journal of Epidemiology, 36, 1126-1135. https://doi.org/10.1093/ije/dym138 
[2] Dale, W.M. (2008) The Effects of Ionizing Radiations on Enzymes in Vitro. Ciba Foundation Symposium-Ionizion Radiations and Cell Metabolism, 25-37. https://doi.org/10.1002/9780470719008.ch3

[3] Modan, B., Keinan, L., Blumstein, T. and Sadetzki, S. (2000) Cancer Following Cardiac Catheterization in Childhood. International Journal of Epidemiology, 29, 424428. https://doi.org/10.1093/intjepid/29.3.424

[4] Lotze, M.T. and Tracey, K.J. (2005) High-Mobility Group Box 1 Protein (HMGB1): Nuclear Weapon in the Immune Arsenal. Nature Reviews Immunology, 5, 331-342. https://doi.org/10.1038/nri1594

[5] Spalding, K.L., Arner, E., Westermark, P.O., Bernard, S., Buchholz, B A., Bergmann, O., Blomqvist, L., Hoffstedt, J., Näslund, E., Britton, T., Concha, H., Hassan, M., Rydén, M., Frisén, J. and Arner, P. (2008) Dynamics of Fat Cell Turnover in $\mathrm{Hu}$ mans. Nature, 453, 783-787. https://doi.org/10.1038/nature06902

[6] Henning, R.J., Johnson, G.T., Coyle, J.P. and Harbison, R.D. (2017) Acrolein Can Cause Cardiovascular Disease: A Review. Cardiovascular Toxicology. https://doi.org/10.1007/s12012-016-9396-5

[7] Aronow, W.S. (2014) Association of Peripheral Arterial Disease with All-Cause Mortality, Cardiovascular Mortality and Cardiovascular Events. Angiology: Open Access, 2, e105. https://doi.org/10.4172/2329-9495.1000e105

[8] Rosch, P.J. (2008) Cholesterol Does Not Cause Coronary Heart Disease in Contrast to Stress. Scandinavian Cardiovascular Journal, 42, 244-249. https://doi.org/10.1080/14017430801993701

[9] Shireman, R.M. (2003) Cholesterol. Role of Cholesterol in Heart Disease. Encyclopedia of Food Sciences and Nutrition, 1243-1250. https://doi.org/10.1016/B0-12-227055-X/00227-3

[10] Shimizu, Y., Kodama, K., Nishi, N., Kasagi, F., Suyama, A., Soda, M. and Hayashi, M. (2010) Radiation Exposure and Circulatory Disease Risk: Hiroshima and Nagasaki Atomic Bomb Survivor Data, 1950-2003. BMJ, 340, b5349. https://doi.org/10.1136/bmj.b5349

[11] Arner, P., Bernard, S., Salehpour, M., Possnert, G., Liebl, J., Steier, P., Buchholz, B.A., Eriksson, M., Arner, E., Hauner, H., Skurk, T., Rydén, M., Frayn, K.N. and Spalding, K.L. (2011) Dynamics of Human Adipose Lipid Turnover in Health and Metabolic Disease. Nature, 478, 110-113. https://doi.org/10.1038/nature10426

\section{Scientific Research Publishing}

Submit or recommend next manuscript to SCIRP and we will provide best service for you:

Accepting pre-submission inquiries through Email, Facebook, LinkedIn, Twitter, etc. A wide selection of journals (inclusive of 9 subjects, more than 200 journals)

Providing 24-hour high-quality service

User-friendly online submission system

Fair and swift peer-review system

Efficient typesetting and proofreading procedure

Display of the result of downloads and visits, as well as the number of cited articles

Maximum dissemination of your research work

Submit your manuscript at: http://papersubmission.scirp.org/

Or contact jbm@scirp.org 